\title{
Inflammatory and Antioxidant Pattern Unbalance in "Clopidogrel-Resistant" Patients during Acute Coronary Syndrome
}

\author{
Raffaele Caruso, ${ }^{1}$ Silvia Rocchiccioli, ${ }^{2}$ Anna Maria Gori, ${ }^{3,4,5}$ \\ Antonella Cecchettini, ${ }^{2,6}$ Betti Giusti, ${ }^{3}$ Guido Parodi, ${ }^{3}$ Lorena Cozzi, ${ }^{1}$ \\ Rossella Marcucci, ${ }^{3}$ Marina Parolini, ${ }^{1}$ Ilaria Romagnuolo, ${ }^{3}$ \\ Lorenzo Citti, ${ }^{2}$ Rosanna Abbate, ${ }^{3}$ and Oberdan Parodi ${ }^{1,2}$ \\ ${ }^{1}$ National Research Council, Institute of Clinical Physiology, Cardiothoracic and Vascular Department, \\ Niguarda Ca' Granda Hospital, Piazza Ospedale Maggiore 3, 20162 Milan, Italy \\ ${ }^{2}$ National Research Council, Institute of Clinical Physiology, Via Moruzzi 1, 56124 Pisa, Italy \\ ${ }^{3}$ Department of Invasive Cardiology 1, Careggi Hospital, University of Florence, Largo Brambilla 3, 50134 Florence, Italy \\ ${ }^{4}$ Department of Invasive Cardiology 1, Careggi Hospital, Largo Brambilla 3, 50134 Florence, Italy \\ ${ }^{5}$ IRCCS, Fondazione Don Gnocchi, Via di Scandicci 269, 50143 Firenze, Italy \\ ${ }^{6}$ Department of Clinical and Experimental Medicine, University of Pisa, Via Roma 5, 56100 Pisa, Italy
}

Correspondence should be addressed to Oberdan Parodi; oberdan.parodi@virgilio.it

Received 20 November 2014; Revised 30 January 2015; Accepted 2 March 2015

Academic Editor: Dianne Cooper

Copyright (c) 2015 Raffaele Caruso et al. This is an open access article distributed under the Creative Commons Attribution License, which permits unrestricted use, distribution, and reproduction in any medium, provided the original work is properly cited.

\begin{abstract}
Background. In acute coronary syndrome (ACS), inflammation and redox response are associated with increased residual platelet reactivity (RPR) on clopidogrel therapy. We investigated whether clopidogrel interaction affects platelet function and modulates factors related to inflammation and oxidation in ACS patients differently responding to clopidogrel. Material and Methods. Platelet aggregation was measured in 29 ACS patients on dual (aspirin/clopidogrel) antiplatelet therapy. Nonresponders (NR) were defined as RPR $\geq 70 \%$ by ADP. Several inflammatory and redox parameters were assayed and platelet proteome was determined. Results. Eight (28\%) out of 29 ACS patients resulted NR to clopidogrel. At 24 hours, the levels of Th2-type cytokines IL-4, IFN $\gamma$, and MCP-1 were higher in NR, while blood GSH $\left(r-G_{-} H_{b l}\right)$ levels were lower in NR than responders (R). Proteomic analysis evidenced an upregulated level of platelet adhesion molecule, CD226, and a downregulation of the antioxidant peroxiredoxin-4. In R patients the proinflammatory cytokine IL-6 decreased, while the anti-inflammatory cytokine IL-1Ra increased. Conclusions. In patients with high RPR on clopidogrel therapy, an unbalance of inflammatory factors, platelet adhesion molecules, and circulatory and platelet antioxidant molecules was observed during the acute phase. Proinflammatory milieu persists in nonresponders for a long time after the acute event while antioxidant blood factors tend to conform to normal responsiveness.
\end{abstract}

\section{Introduction}

Since platelet activation plays a critical point in the pathogenesis of ACS [1], antiplatelet treatments are frequently used in patients with acute coronary syndrome (ACS), in order to reduce ischemic events. The dual antiplatelet therapy that combines aspirin (acetylsalicylic acid, ASA) and a platelet $\mathrm{P} \mathrm{Y}_{12}$ receptor inhibitor is the standard antithrombotic strategy in the treatment of ACS and for the prevention of thrombotic complications subsequent to percutaneous coronary intervention (PCI) [2]. Despite the availability of newer platelet $\mathrm{P} 2 \mathrm{Y}_{12}$ receptor inhibitors, clopidogrel remains widely used, also because it allows a considerable costcontainment. However, notwithstanding significant benefits reported with dual antiplatelet treatment in major clinical trials, the occurrence of major ischemic events, including stent thrombosis, remains a serious clinical problem [3]. Several studies have revealed variability of antiplatelet efficacy based 
on the so-called "clopidogrel resistance" [4-6]. Lack of adequate platelet inhibition to clopidogrel might be associated with many factors including patient noncompliance, drug interactions, alternative mechanisms of platelet activation, metabolic pathway alterations, and also polymorphisms of genes that play a role in clopidogrel metabolism $[7,8]$.

Inflammation plays an important role in the pathophysiology and prognosis of ACS. The extent of inflammatory response is crucial in haemostatic system, throughout increased platelet reactivity and endothelial dysfunction, factors which are potentially involved in the variability of antiplatelet efficacy [9]. In this context, elevated leukocyte count and high levels of anti-inflammatory cytokine interleukin- (IL-) 10 are reported as important factors associated with the probability of low clopidogrel responsiveness [10]. Differently, an inverse relationship between antiinflammatory cytokine IL- 4 and the residual platelet reactivity was reported in ACS patients on dual antiplatelet therapy [11], suggesting a complex interaction between inflammatory pathways and response to clopidogrel.

Experimental and clinical studies suggest also a pivotal role of reactive oxidant species (ROS) in the mechanism of platelet activation [12]. ROS are implicated in platelet activation by inactivating nitric oxide (NO) and releasing platelet agonists and proatherogenic molecules [12]. In particular, the main antioxidant amino-thiol glutathione (GSH) has a central role in the redox modulation of platelet activity [13], and it is known that deficiencies of enzymes that are involved in GSH synthesis are associated with cardiovascular events [14]. Moreover, in human platelets, NO pathway is a target of the prooxidant amino-thiol homocysteine (Hcy), which promotes the reduction of $\mathrm{NO}$, platelet hyperactivation, and other thrombogenic processes $[15,16]$.

More recently, with the omics booming, proteomics approaches have been often adopted to investigate platelet proteome. In a previous proteomics study it was reported that ASA-resistant patients show an increased plasma expression of vitamin D-binding protein isotypes [17]. This was associated with the failure of ASA to prevent both thromboxane A2 production and platelet activation, unmasking a potential mechanism involved in ASA resistance. Moreover, platelet protein profiling of patients with stable angina under clopidogrel therapy shows different expression of proteins involved in the cytoskeleton rearrangement, in the energetic metabolism, and in the oxidative stress [18].

The aim of this study was to associate several soluble circulating inflammatory markers and redox factors in ACS patients with different responses to clopidogrel treatment. In a restricted subgroup of patients [6], mass spectrometrybased protein profile of platelet proteome was investigated and information on oxidative, inflammatory pathways and energetic metabolism was obtained.

\section{Material and Methods}

2.1. Population Enrolment and Platelet Reactivity Assessment. Twenty-nine ACS patients undergoing PCI, stent implantation in dual antiplatelet therapy with clopidogrel, and
ASA were enrolled at the University Hospital of Careggi in Florence. Platelet reactivity assessment was made by light transmittance aggregometry (APACT4, Helena Laboratories, Milan, Italy) using adenosine diphosphate (ADP) as an agonist [19]. Blood samples anticoagulated with $0.109 \mathrm{M}$ sodium citrate (ratio, 9:1) were obtained 24 hours, 1 week, and 1 month after a $600 \mathrm{mg}$ clopidogrel loading dose. Platelet-rich plasma, obtained by centrifuging whole blood for 10 minutes at $200 \mathrm{~g}$, was stimulated with $10 \mu \mathrm{M}$ ADP. The $100 \%$ line was set using platelet-poor plasma and the 0 baseline established with platelet-rich plasma (adjusted from $180 \times 109 / \mathrm{L}$ to $300 \times$ 109/L). Platelet aggregation (according to the Born method) was evaluated considering the maximal percentage of platelet aggregation in response to stimulus. Runs of 10 minutes were set for all the agonists used in the LTA test in order to better characterize the profile of aggregation/disaggregation. Maximum aggregation was used in order to measure the entity of platelet inhibition. The coefficient of variation of ADP platelet aggregation was $6.8 \%$. Platelet reactivity was evaluated within 24 hours from clopidogrel loading. High residual platelet reactivity by ADP test was defined as platelet aggregation of $70 \%$ or greater [20].

The study complied with the principles of the Declaration of Helsinki, and Careggi Hospital Ethics Committee approved the study protocol. All the patients gave written informed consent to participate in the study. Patients with poor adherence to the prescribed therapy were excluded from the study.

2.2. Assessment of Inflammatory Parameters. In all enrolled ACS patients, blood $\left(\mathrm{Na}^{2+}\right.$-EDTA and $4 \%$ trisodium citrate as anticoagulants) samples were collected at 24 hours, 1 week, and 1 month from administration of dual antiplatelet therapy for the assessment of a panel of inflammatory mediators, consisting of cytokines associated with Th1/Th2-type T cells (interleukin- (IL-) 4, IL-12, and interferon-gamma (IFN- $\gamma$ )), pro- (IL-6 and tumor necrosis factor alpha (TNF- $\alpha$ )), and anti-inflammatory cytokines (IL-10 and receptor antagonist of IL-1 (IL-1ra)), and chemotactic molecules (interferongamma-induced protein 10 (IP-10 or CXCL10), interferoninducible $\mathrm{T}$ cell alpha chemoattractant (I-TAC or CXCL11), monocyte chemotactic protein-1 (MCP-1), and macrophage inflammatory protein- $1 \beta$ (MIP-1 $\beta$ or CCL 4$)$ ).

Plasma inflammatory mediators were determined by BioPlex cytokine assay (R\&D Systems, Minneapolis, MN, USA) according to manufacturer's instructions.

2.3. Assessment of Redox Status. In 23 out of 29 enrolled ACS patients, additional blood samples were collected at 24 hours, 1 week, and 1 month after administration of dual antiplatelet therapy for the assessment also of reduced and total aminothiols, Hcy, and GSH, and the activities of GSH peroxidase type-1 (GPx-1). Blood reduced GSH (r-GSH $\mathrm{Gl}_{\mathrm{bl}}$ ) level was determined by prompt acidification of whole blood immediately after blood sample collection according to method previously described [14]. As reduced GSH levels in plasma are low (1-2\%), the reduced GSH concentration in whole blood can reflect GSH content inside the cellular fraction of 


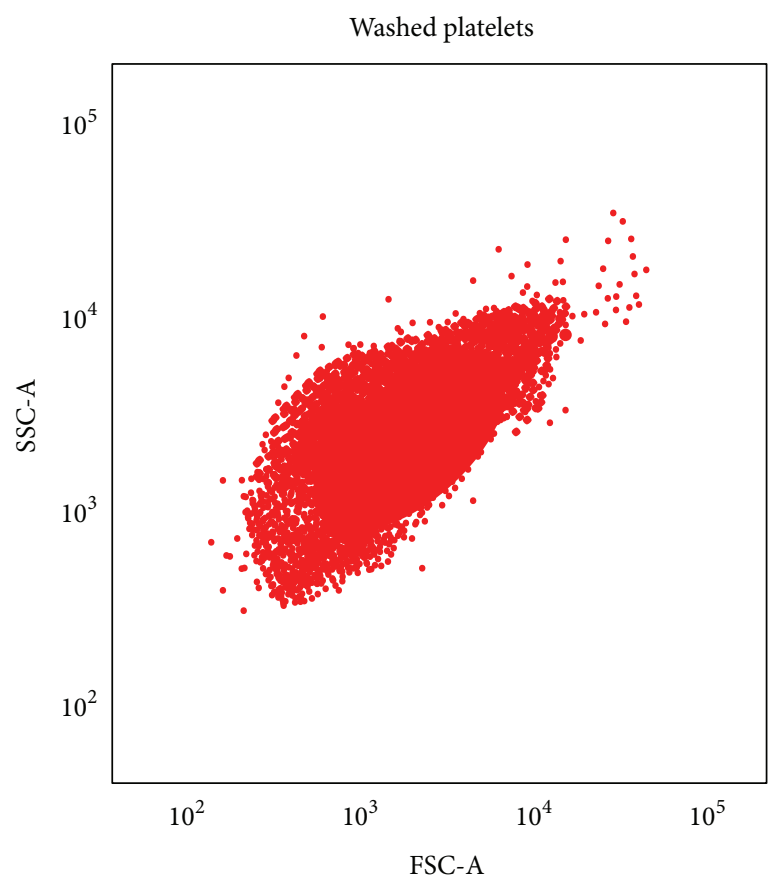

(a)

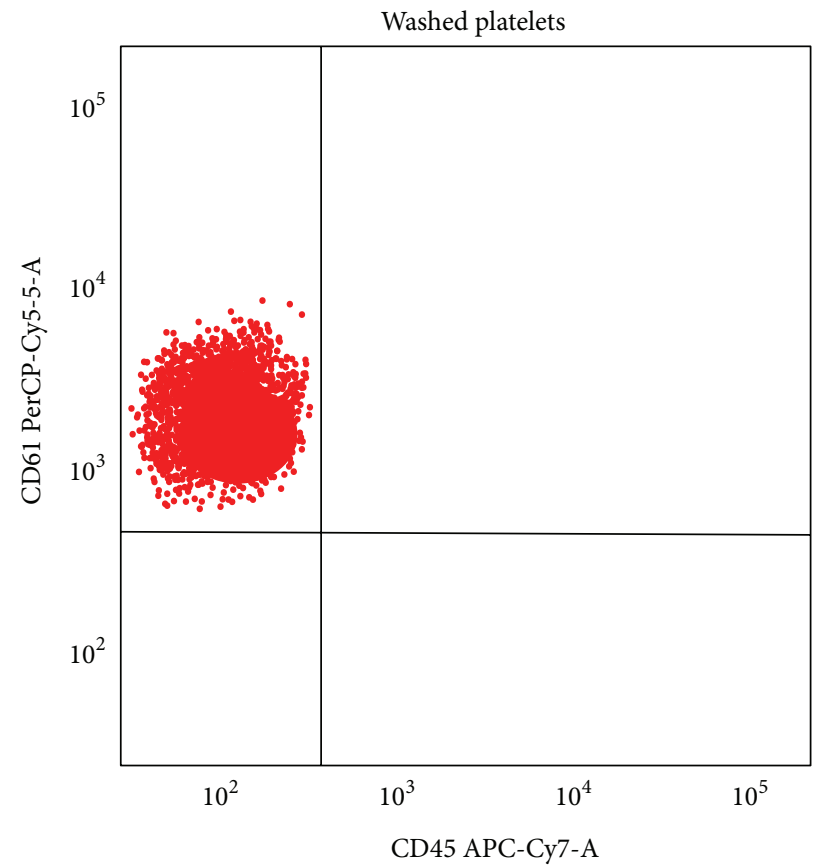

(b)

FIGURE 1: Flow cytometric determination of white blood cell (WBC) contamination of platelet suspensions. Flow cytometric analysis after staining with antibodies specific for CD61 (PerCP-Cy5-5) and for CD45 (APC-Cy7). In (a), the box includes cellular suspension according to SSC and FSC. In (b) the CD61+/CD45+ events gated on P1 are shown in the right upper quadrant.

blood. Plasma reduced and total forms of Hcy and blood total GSH were determined according to methods validated in our laboratory [14]. The total form of GSH measured in our study includes the oxidized GSH, all conjugated forms of GSH (protein-bound GSH and GSH-mixed disulfides), produced through oxidative processes or thiol-disulfide exchange reactions, and reduced free GSH. Thiol separation was performed by high-performance liquid chromatography (HPLC) method (ProStar-Varian, Surrey, UK). Erythrocyte GPx-1 was determined using t-butyl hydroperoxide (SIGMA, Steinheim, Germany) as substrate [21]. GPx-1 activities were determined in diluted purified red blood cells, stored frozen up to analysis which was performed within 1 month from storage.

2.4. Platelet Isolation, Protein Extraction, Reduction, Alkylation, and Digestion. In a restricted population of 12 ACS patients (6 nonresponders), platelet-rich plasma (PRP) was obtained from whole blood at 24 hours after administration of dual antiplatelet therapy. PRP was prepared by centrifuging blood samples at $150 \mathrm{~g}$ for 10 minutes. Then it was removed and platelet-poor plasma was prepared by further centrifugation at $3,000 \mathrm{~g}$ for 3 minutes. PRP was adjusted with autologous platelet-free plasma to reach a platelet count between $180000 \mathrm{plt} / \mu \mathrm{L}$ and $300,000 \mathrm{plt} / \mu \mathrm{L}$. The purity of isolated platelets was confirmed by flow cytometry on a Becton Dickinson FACS can instrument.

White blood cells in platelet suspension were identified through their expression of CD45. A volume of $10 \mu \mathrm{L}$ of platelet suspension was incubated for $20 \mathrm{~min}$ in the dark with
(1) peridinin chlorophyll protein-cyanin-5.5- (PerCP-Cy5.5-) labelled monoclonal antibodies against human CD61 (Becton Dickinson, San Jose, USA); (2) allophycocyanin-cyanin-7(APC-Cy7-) labelled monoclonal antibodies against human CD45 (Becton Dickinson, San Jose, USA) (Figure 1).

PRP samples were centrifuged at $800 \mathrm{~g}$ for $15 \mathrm{~min}$ and pellets of platelets were resuspended in $350 \mu \mathrm{L}$ of lysis solution (Tris/HCl 50 mM, 0.1\% Triton-X100). Detergent was removed using detergent removal columns (Pierce) following manufacturer instructions. Briefly, protein extracts were placed on the column and incubated for two minutes. Columns were centrifuged for two minutes to collect detergent-free samples. BCA assay was used to evaluate total protein concentration. $100 \mu \mathrm{L}$ of protein extract $(1 \mu \mathrm{g} / \mu \mathrm{L}$ concentration) was added to $100 \mu \mathrm{L}$ of $40 \mathrm{mM}$ of ammonium hydrogen carbonate $(\mathrm{pH}=8)$. Reduction was obtained by adding $1 \mu \mathrm{L}$ of $1 \mathrm{M}$ dithiothreitol to each sample, with an incubation of $20 \mathrm{~min}$ at $80^{\circ} \mathrm{C}$. For alkylation, $20 \mu \mathrm{L}$ of $100 \mathrm{mM}$ iodoacetamide was added to the samples and incubated for $30 \mathrm{~min}$ at $37^{\circ} \mathrm{C}$. Trypsin digestion was performed incubating samples with $8 \mathrm{microL}$ of $0.25 \mathrm{mg} / \mathrm{ml}$ solution at $37^{\circ} \mathrm{C}$ overnight.

2.5. LC-MS/MS Analysis. Chromatographic separation of peptides was performed using an ultimate 3000 nano-HPLC system (LC Packings, DIONEX, USA). $100 \mu \mathrm{L}$ of sample was added to a solution composed by $2 \% \mathrm{CH}_{3} \mathrm{CN}$ and $0.1 \%$ formic acid up to $200 \mu \mathrm{L}$ of final volume. The loading pump preconcentrated the sample in a precolumn cartridge (PepMap$100 \mathrm{C} 185 \mathrm{~mm} 100 \mathrm{~A}, 30 \mathrm{~mm}$ id $\times 5 \mathrm{~mm})$. Chromatographic 
separation of peptides was performed using a C18 PepMap100 column $(15 \mathrm{~cm} \times 75 \mathrm{~mm}$ id, LC Packings DIONEX) equilibrated at $45^{\circ} \mathrm{C}$ with solvent A (water/acetonitrile 98/2 vol/vol, $0.1 \%$ formic acid) at a flow rate of $300 \mathrm{~nL} \mathrm{~min}^{-1}$. Runs were performed under 40 min linear gradient from 10 to $45 \%$ of solvent $\mathrm{B}$ (water $/ \mathrm{CH}_{3} \mathrm{CN} 2 / 98 \mathrm{vol} / \mathrm{vol}, 0.1 \%$ formic acid) followed by $10 \mathrm{~min}$ of a purge step at $95 \%$ of B before a $20 \mathrm{~min}$ reequilibration step to the starting conditions. The column was directly coupled to TripleTOF 5600 System (AB SCIEX, Toronto, Canada), equipped with a DuoSpray ion source (AB SCIEX, Toronto, Canada). Eluted peptides were directly processed using TripleTOF 5600 mass spectrometer (AB SCIEX, Toronto, Canada). The mass spectrometer was controlled by Analyst 1.6.1 software (AB SCIEX, Toronto, Canada). For positive ionization, ion source parameters were the following: spray voltage $3 \mathrm{KV}$, temperature $150^{\circ} \mathrm{C}$, curtain gas $25 \mathrm{psi}$, GS1 10 psi. For information dependent acquisition (IDA) analysis, survey scans were acquired in $250 \mathrm{~ms}$. Dynamic exclusion was set for $1 / 2$ of peak width $(\sim 8 \mathrm{~s})$, and then the precursor was refreshed off the exclusion list.

2.6. Protein Identification and Label-Free Comparative Analysis. MS/MS data were processed with ProteinPilot Software (AB SCIEX, Toronto, Canada), using the Paragon and Pro Group Algorithms and SwissProt 2013 as protein database for Homo sapiens species. The false discovery rate analysis was done using the integrated tools in ProteinPilot software and a confidence level of $95 \%$ was set. The statistical comparative analysis was performed using MarkerView Software 1.2.1 (AB SCIEX). The ion chromatograms of high confidence peptides identified by ProteinPilot were extracted using PeakView Software and then MS peak areas and identifications were imported into MarkerView Software.

2.7. Statistical Analysis. Continuous variables were presented as median and interquartile ranges and categorical data as frequency (\%). Group comparisons (responders versus nonresponders) of the clinical and biochemical characterizations were performed by unpaired Student's $t$-test for continuous variables or Mann-Whitney $U$ test for not normally distributed variables, and Chi-square or Fisher's exact test for categorical variables. Time-dependent changes (24 hours, 1 week, and 1 month) in groups were assessed by nonparametric Friedman test ( $P$ for time); pairwise post hoc comparisons were performed by using the Wilcoxon signedrank test with Bonferroni correction.

Pearson's correlation coefficient $(r)$ and the equivalent nonparametric Spearman's rho (rho) correlation coefficient were used to analyze the association between biochemical variables.

For mass spectrometric data, principal component analysis (PCA) was performed with MarkerView 1.2 software in order to evidence groupings among the data set. All profile areas were normalized using total area sum. The two groups (responders $(\mathrm{R})$ and nonresponders (NR)) were compared with $t$-test with a threshold of $95 \%(P$ value $=0.05)$ and fold change $>2$. A $P$ value $<0.05$ was considered statistically significant.

\section{Results}

3.1. Clinical Characteristics of Clopidogrel Nonresponder and Responder Patients. The median age of enrolled ACS patients was 75 (71-98) years. For sixteen (55\%) patients ST-segment elevation myocardial infarction was characterized by electrocardiography, and 8 (28\%) patients showed three-vessel coronary artery disease. Eight (28\%) out of 29 ACS patients were considered NR to clopidogrel. The clinical characteristics of $\mathrm{R}$ and NR patients are summarised in Table 1 .

The main clinical features of $\mathrm{R}$ and $\mathrm{NR}$ patients were similar, with exception of bare metal coronary stents and diabetes that were more frequent in NR patients. The medical history was comparable too, as well as therapy (in particular the administration of GPIIb/IIIa inhibitors) associated with clopidogrel-based antiplatelet treatment (Table 1).

\subsection{Inflammatory and Redox Patterns in Clopidogrel Nonre-} sponder and Responder Patients during Early Phases of Dual Antiplatelet Treatment. The inflammatory data concerning the acute phase of ACS at 24 hours after clopidogrel loading dose are reported in Table 2.

NR patients showed higher levels of IL- 4 and IFN $\gamma$ that are both associated with the differentiation of naive $\mathrm{T}$ cell $\mathrm{Th} 1$ and Th2. The levels of anti-inflammatory cytokine IL-10 were higher in NR than in R, while the levels of proinflammatory cytokines, IL- 6 and TNF $\alpha$, were comparable between the two groups. Among chemokines, MIP-1 $\beta$ was more concentrated in NR platelets, while I-TAC was present in higher levels in R patients.

Among inflammatory variables, in all patients, IL-4 levels were positively related only with MIP- $1 \beta$ levels ( $r$ ho $=0.56$, $P=0.008$ ), while, in NR patients, MIP-1 $\beta$ levels were related with IL-10 levels (rho $=0.93, P=0.001$ ).

The redox data associated with clopidogrel resistance during the acute phase of ACS at 24 hours after clopidogrel loading dose are summarized in Table 3.

The levels of aminothiols, in both plasma and whole blood, were equivalent in the two patient groups, with the exception of the $\mathrm{r}-\mathrm{GSH}_{\mathrm{bl}}$, which was significantly lower in NR and positively related with plasma total GSH levels (rho = $0.51, P=0.014)$. GPx-1 activities were also comparable between groups.

Among all patients, IL-4 levels were negatively related to plasma reduced GSH (rho $=-0.59, P=0.004$ ) and TNF- $\alpha$ levels were negatively associated with $\mathrm{r}-\mathrm{GSH}_{\mathrm{bl}}(\mathrm{rho}=$ $-0.52, P=0.016)$. Differently, I-TAC levels were positively correlated to plasma reduced GSH (rho $=0.56, P=0.008)$.

3.3. Inflammatory and Redox Profiles in Responders and Nonresponders. Follow-up evaluation of inflammatory and redox profiles was assessed in 19 ACS patients (24 hours, one week, and one month after clopidogrel loading dose). In NR, the levels of inflammatory parameters were unchanged during the first month after dual antiplatelet therapy administration, with the exception of IL- 6 that tended to decrease after one week from the acute phase. At variance, $R$ patients showed 
TABLE 1: Clinical characteristics between clopidogrel-responder and -nonresponder patients.

\begin{tabular}{|c|c|c|c|}
\hline & Responders $(n=21)$ & Nonresponders $(n=8)$ & $P$ \\
\hline Age, years & $73(60-80)$ & $78(71-83)$ & 0.341 \\
\hline Male, $n(\%)$ & $15(71)$ & $4(50)$ & 0.242 \\
\hline BMI, $\mathrm{kg} / \mathrm{m}^{2}$ & $25(23-27)$ & $26(24-31)$ & 0.241 \\
\hline STEMI, $n(\%)$ & $11(52)$ & $5(63)$ & 0.697 \\
\hline NSTEMI, $n(\%)$ & $10(48)$ & $3(37)$ & 0.697 \\
\hline Lesion coronary artery, $n$ & $2(1-3)$ & $1(1-2)$ & 0.189 \\
\hline Three-vessel coronary artery disease, $n(\%)$ & $7(33)$ & $1(13)$ & 0.381 \\
\hline Killip class, $n(\%)$ & & & 0.804 \\
\hline 0 & $2(10)$ & $1(13)$ & \\
\hline 1 & $17(85)$ & $7(88)$ & \\
\hline 2 & $1(5)$ & $0(0)$ & \\
\hline \multicolumn{4}{|l|}{ Stent implantation, $n(\%)$} \\
\hline DES & $11(52)$ & $1(13)$ & 0.093 \\
\hline BMS & $9(43)$ & $8(100)$ & 0.009 \\
\hline \multicolumn{4}{|l|}{ Risk factors, $n(\%)$} \\
\hline Smoking & $8(38)$ & $1(13)$ & 0.371 \\
\hline Hypertension & $13(62)$ & $5(63)$ & 1.000 \\
\hline Hyperlipidemia & $4(19)$ & $3(38)$ & 0.357 \\
\hline Diabetes mellitus & $3(14)$ & $5(63)$ & 0.019 \\
\hline Family history of CAD & $1(5)$ & $1(13)$ & 0.483 \\
\hline \multicolumn{4}{|l|}{ Medical history, $n(\%)$} \\
\hline PCI & $1(5)$ & $1(13)$ & 0.483 \\
\hline CABG & $0(0)$ & $1(13)$ & 0.276 \\
\hline LEAD & $2(10)$ & $0(0)$ & 1.000 \\
\hline Ictus & $0(0)$ & $0(0)$ & - \\
\hline Renal failure & $1(5)$ & $0(0)$ & 1.000 \\
\hline Atrial fibrillation & $2(10)$ & $1(13)$ & 1.000 \\
\hline COPD & $2(10)$ & $1(13)$ & 1.000 \\
\hline \multicolumn{4}{|l|}{ Medical therapy, $n(\%)$} \\
\hline Ca-antagonist & $3(14)$ & $1(13)$ & 1.000 \\
\hline Ca-channel blockers & $0(0)$ & $0(0)$ & - \\
\hline $\mathrm{ACEi}$ & $13(62)$ & $4(50)$ & 0.683 \\
\hline $\mathrm{ARB}$ & $2(10)$ & $1(13)$ & 1.000 \\
\hline$\beta$-blockers & $10(48)$ & $5(63)$ & 0.682 \\
\hline Statins & $21(100)$ & $8(100)$ & - \\
\hline GPIIb/IIIa inhibitors & $7(33)$ & $3(38)$ & 1.000 \\
\hline
\end{tabular}

Data are expressed as median and interquartile range (25th-75th) or number (percentage).

ACEi: angiotensin-converting enzyme inhibitor; ARB: angiotensin receptor blockers; BMI: body mass index; Ca: calcium; BMS: bare metal coronary stent; CABG: coronary artery by-pass grafting; CAD: coronary artery disease; COPD: chronic obstructive pulmonary disease; DES: drug-eluting stent; LEAD: lower extremity arterial disease; GP: glycoprotein; PCI: percutaneous coronary intervention; NSTEMI; non-ST-segment elevation myocardial infarction.

significant changes of IL-6, IL-1ra, and IL-4 levels over time (Figure 2).

In particular, a reduction of IL-6 levels was observed in $\mathrm{R}$ patients (Figure 2(a)) resulting lower one month after treatment than in NR patients $[0.6(0.0-6.1)$ and 11.3 (3.3$54.6) \mathrm{pg} / \mathrm{mL}$ of IL-6 in R and NR patients, respectively $P=$ 0.059]. Differently, an increment of the IL-1ra levels was observed at one week in $\mathrm{R}$ with respect to NR patients (Figure 2(b)). In addition, responders showed a significant increase of IL-4 levels one week after treatment, returning to baseline values at one month (Figure 2(c)). The levels of chemotactic molecules did not change over time in both groups with respect to those observed in the acute phase (Table 4).

Among redox variables, NR patients showed significant changes with respect to $\mathrm{R}$ patients of the $\mathrm{r}-\mathrm{GSH}_{\mathrm{bl}}$ levels, which tended to reequilibrate after one month (Figure 3(a)). Likewise, the levels of blood total GSH $\left(\mathrm{t}-\mathrm{GSH}_{\mathrm{bl}}\right)$ were reduced one week after dual antiplatelet therapy administration (Figure 3(b)). In NR, the activity of GPx-1 reached an activity comparable to that of $\mathrm{R}$ patients within one week (Figure 3(c)). The levels of Hcy did not change over time in both groups as compared to the acute phase (Table 4 ). 
TABLE 2: Inflammatory pattern at 24 hours from daily administration of dual antiplatelet treatment in clopidogrel responders and nonresponders.

\begin{tabular}{lccc}
\hline & All cases $(n=29)$ & Responders $(n=21)$ & Nonresponders $(n=8)$ \\
\hline Th1/Th2 milieu & & & $P$ \\
IL-4, pg/mL & $0.66(0.27-1.28)$ & $0.57(0-0.76)$ & $1.28(0.84-4.67)$ \\
IL-12, pg/mL & $69.1(44.1-106.2)$ & $59.5(36.5-101.6)$ & $91.4(63.0-119.7)$ \\
IFN $\gamma, \mathrm{pg} / \mathrm{mL}$ & $63.2(49.4-99.1)$ & $55.2(43.9-88.5)$ & $93.1(60.2-127.3)$ \\
Proinflammatory cytokines & & & 0.003 \\
IL-6, pg/mL & $5.7(3.2-19.9)$ & $5.1(3.2-20.0)$ & $9.7(3.5-1406.4)$ \\
TNF- $\alpha, \mathrm{pg} / \mathrm{mL}$ & $2.9(0.7-10.9)$ & $2.4(0-5.5)$ & $9.4(0.8-23.2)$ \\
Anti-inflammatory cytokines & & & 0.381 \\
IL-1ra, pg/mL & $750(595-1222)$ & $713(563-1093)$ & 0.283 \\
IL-10, pg/mL & $25.4(13.1-34.5)$ & $20.3(11.2-28.7)$ & $32.2(25.7-38.3)$ \\
Chemokines & & & 0.218 \\
I-TAC, pg/mL & $165(69-206)$ & $177(162-228)$ & 0.079 \\
IP10, pg/mL & $965(726-2200)$ & $949(726-2223)$ & $10-170)$ \\
MCP-1, pg/mL & $17.3(14.9-31.8)$ & $17.3(14.8-31.8)$ & 0.080 \\
MIP-1 $\beta, \mathrm{pg} / \mathrm{mL}$ & $94.5(66.7-115.1)$ & $78.1(58.2-108.4)$ & 0.897 \\
\hline
\end{tabular}

Data are expressed as median and interquartile range (25th-75th).

IL: interleukin; IFN: interferon; IP10: interferon-gamma-induced protein 10; I-TAC: interferon-inducible T cell alpha chemoattractant; MCP-1: monocyte chemotactic protein-1; MIP-1 $\beta$ : macrophage inflammatory protein-1 $\beta$; TNF: tumor necrosis factor; Th1/Th2: T helper type-1 or type- 2 cells.

TABLE 3: Redox status at 24 hours from daily administration of dual antiplatelet treatment between clopidogrel responders and nonresponders.

\begin{tabular}{|c|c|c|c|c|}
\hline & All cases $(n=23)$ & Responders $(n=17)$ & Nonresponders $(n=6)$ & $P$ \\
\hline $\mathrm{r}-\mathrm{Hcy} \mathrm{pl}, \mu \mathrm{mol} / \mathrm{L}$ & $0.19(0.14-0.20)$ & $0.20(0.15-0.25)$ & $0.17(0.10-0.19)$ & 0.227 \\
\hline $\mathrm{t}-\mathrm{Hcy}_{\mathrm{pl}}, \mu \mathrm{mol} / \mathrm{L}$ & $13.5(8.6-15.3)$ & $13.0(8.6-15.2)$ & $13.9(9.8-16.6)$ & 0.812 \\
\hline $\mathrm{r}-\mathrm{GSH}_{\mathrm{pl}}, \mu \mathrm{mol} / \mathrm{L}$ & $3.93(1.64-5.59)$ & $4.25(1.54-6.24)$ & $3.52(1.71-4.50)$ & 0.412 \\
\hline $\mathrm{t}-\mathrm{GSH}_{\mathrm{pl}}, \mu \mathrm{mol} / \mathrm{L}$ & $6.10(2.78-7.08)$ & $6.26(3.46-7.08)$ & $3.84(2.60-7.46)$ & 0.560 \\
\hline $\mathrm{r}-\mathrm{GSH}_{\mathrm{bl}}, \mu \mathrm{mol} / \mathrm{L}$ & $426(393-500)$ & $451(410-537)$ & $392(315-431)$ & 0.033 \\
\hline $\mathrm{t}-\mathrm{GSH}_{\mathrm{bl}}, \mu \mathrm{mol} / \mathrm{L}$ & $998(784-1099)$ & $1031(876-1108)$ & $873(716-1054)$ & 0.294 \\
\hline GPx-1, IU/grHb & $12.8(9.3-17.8)$ & $12.6(9.3-13.4)$ & $19.5(8.7-27.5)$ & 0.203 \\
\hline
\end{tabular}

Data are expressed as median and interquartile range (25th-75th).

Bl: blood; GSH: glutathione; GPx-1: glutathione peroxidase type-1; GPx-3: glutathione peroxidase type-3; pl: plasma; r: reduced; t: total.

3.4. Proteomics Analysis of Clopidogrel Responders and Nonresponders. The platelet proteome of 12 ACS patients (6 $\mathrm{R}$ and $6 \mathrm{NR}$ ) was analyzed by LC-MSMS approach 24 hours after clopidogrel loading dose. Individual profiles were obtained in 1 hour of chromatographic separation coupled with electrospray mass spectrometry. 74 proteins related to inflammation, oxidative state, and energetic metabolism were identified with a Protein Score (Confidence) $>95 \%$ and using local false discovery rate analysis $>1 \%$ as stringent criterion to avoid false positives (Figure 4).

Differentially expressed markers were evaluated using MarkerView software, and 3 proteins (CD226, peroxiredoxin-4 (PRDX4), and transferrin (TRFE)) were differently modulated between R and NR patients (Figures 5(a)-5(c)).

\section{Discussion}

In the present study, changes in expression and modulation of inflammation, redox, and platelet molecules were investigated in R and NR to clopidogrel-based antiplatelet treatment patients during ACS. In the acute phase of the coronary syndrome, the IL- 4 and MIP- $1 \beta$ levels were found higher in NR than in R patients. IL-4, a known Th2-type anti-inflammatory cytokine, is crucial to modulate $\mathrm{T}$ cell differentiation and to direct differentiation of human monocytes into antigen presenting specialized cells [21]. The $\mathrm{T}$ cell differentiation into Th1 or Th2 is important in the clinical context of ACS since Thl cells are able to activate monocytes/macrophages, committing them to the so-called "delayed-type hypersensitivity" phenomenon [22], and to induce the expression of factors promoting microthrombosis. Gori et al. [11] reported an inverse relationship between levels of IL-4 and the residual platelet reactivity in ACS patients undergoing PCI on dual antiplatelet therapy. In our study, NR patients showed higher levels of peripheral IL-4, data which seem to exclude a T cell differentiation towards the Thl profile.

MIP-1 $\beta$ is known as CCR5 macrophage receptor ligand, involved in the activating signals for the monocyte recruitment during atherogenesis and in inflammatory processes [23]. Currently, the involvement of MIP-1 $\beta$ and CCR5 signals 
TABLE 4: Time-dependent changes of Hcy and chemotactic molecules levels.

\begin{tabular}{|c|c|c|c|c|c|c|c|c|}
\hline & \multicolumn{4}{|c|}{ Responders } & \multicolumn{4}{|c|}{ Nonresponders } \\
\hline & 24 hours & 1 week & 1 month & $P$ & 24 hours & 1 week & 1 month & $P$ \\
\hline $\mathrm{r}-\mathrm{Hcy}_{\mathrm{pl}}, \mu \mathrm{mol} / \mathrm{L}$ & $0.20(0.15-0.25)$ & $0.20(0.14-0.20)$ & $0.20(0.15-0.30)$ & 0.307 & $0.17(0.10-0.19)$ & $0.18(0.12-0.22)$ & $0.21(0.12-4.48)$ & 0.050 \\
\hline $\mathrm{t}-\mathrm{Hcy}_{\mathrm{pl}}, \mu \mathrm{mol} / \mathrm{L}$ & $13.0(8.6-15.2)$ & $12.1(10.9-14.6)$ & $12.1(10.4-15.7)$ & 0.936 & $13.9(9.8-16.6)$ & $11.6(9.4-13.2)$ & $12.3(9.9-36.2)$ & 0.368 \\
\hline I-TAC, pg/mL & $177(162-228)$ & $207(88-292)$ & $187(89-268)$ & 0.144 & $74(0-170)$ & $76(0-202)$ & $32(0-224)$ & 0.223 \\
\hline IP10, pg/mL & 949 (726-2223) & $986(817-1317)$ & $1060(765-1550)$ & 0.344 & $1532(698-2118)$ & 1135 (877-2764) & 1122 (941-2751) & 0.819 \\
\hline MCP-1, pg/mL & $17.3(14.8-31.8)$ & $19.5(11.0-24.5)$ & $19.5(15.5-31.1)$ & 0.420 & $21.1(15.0-31.3)$ & $41.7(20.1-50.3)$ & $28.1(15.4-31.8)$ & 0.819 \\
\hline MIP- $1 \beta, p g / m L$ & $78.1(58.2-108.4)$ & $65.7(50.1-108.7)$ & $75.4(45.5-94.0)$ & 0.549 & $115.3(96.3-131.3)$ & $99.1(84.8-120.9)$ & $124.6(72.2-140.8)$ & 0.549 \\
\hline
\end{tabular}

Data are expressed as median and interquartile range (25th-75th).

pl: plasma; r: reduced; t: total; I-TAC: interferon-inducible T cell alpha chemoattractant; MCP-1: monocyte chemotactic protein-1; MIP-1 $\beta$ : macrophage inflammatory protein-1 $\beta$; TNF: tumor necrosis factor; Th1/Th2: T helper type 1 or type 2 cells.

$P$ : time-dependent changes ( 24 hours, 1 week, and 1 month) in groups assessed by nonparametric Friedman test.

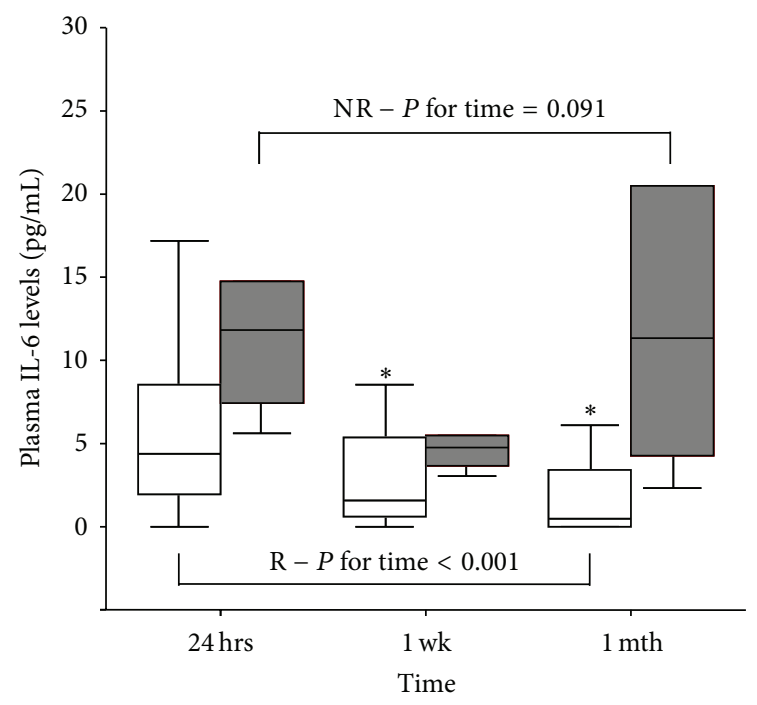

(a)

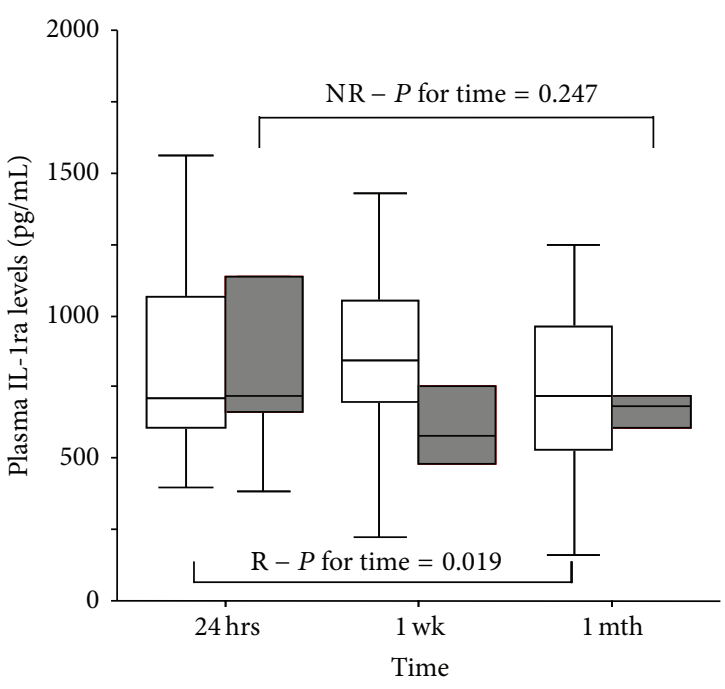

(b)

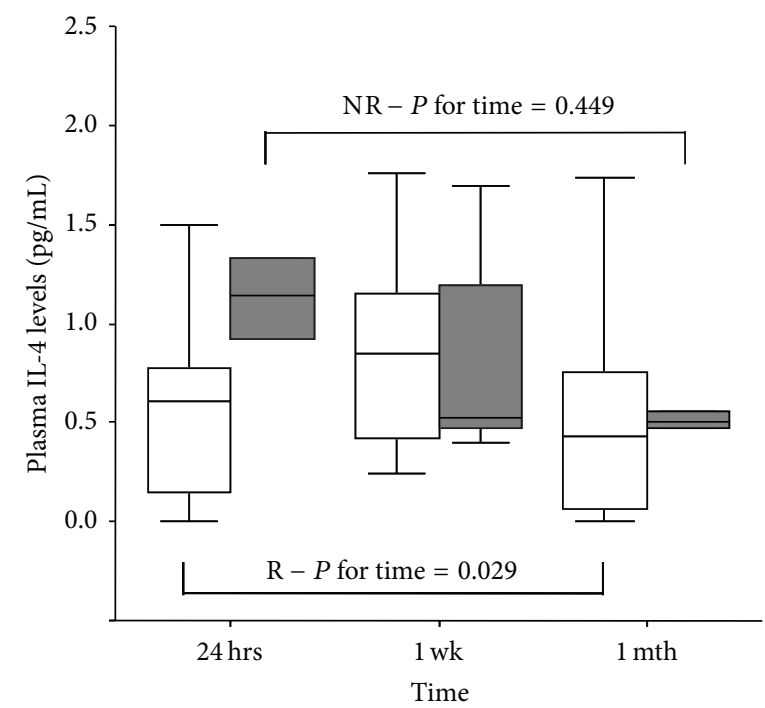

(c)

FIgURE 2: Profile of levels of IL-6 (a), IL-1ra (b), and IL-4 (c) in NR and R patients (R: empty box-plots; NR: dark box-plots). $P$ for time refers to time-dependent changes ( 24 hours, 1 week, and 1 month) in groups assessed by nonparametric Friedman test, ${ }^{*} P<0.025$ versus 24 hrs by Bonferroni adjusted post hoc test for pairwise comparisons. 


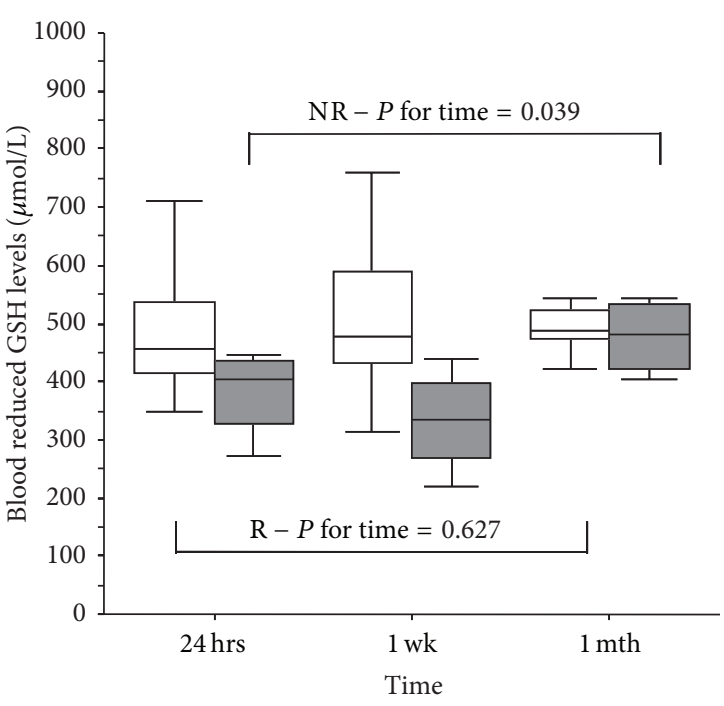

(a)

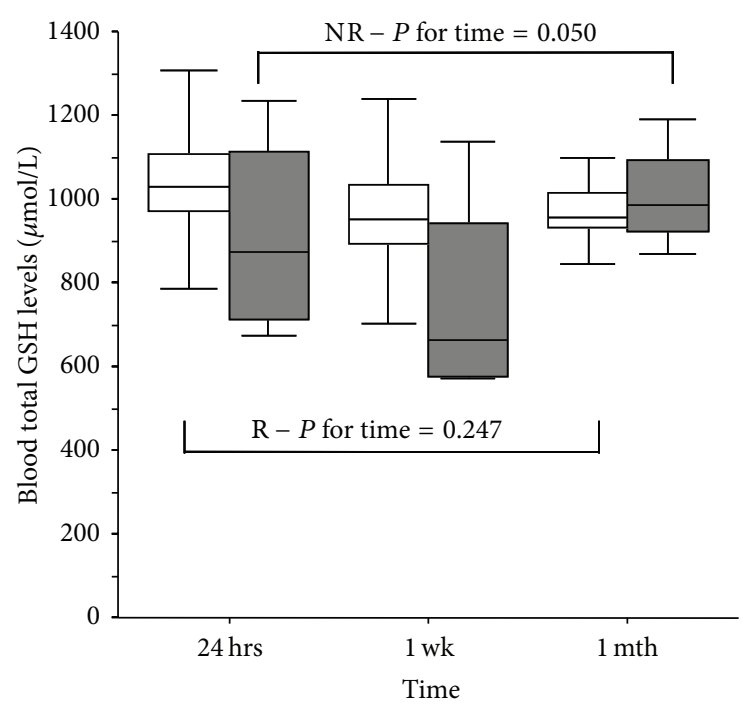

(b)

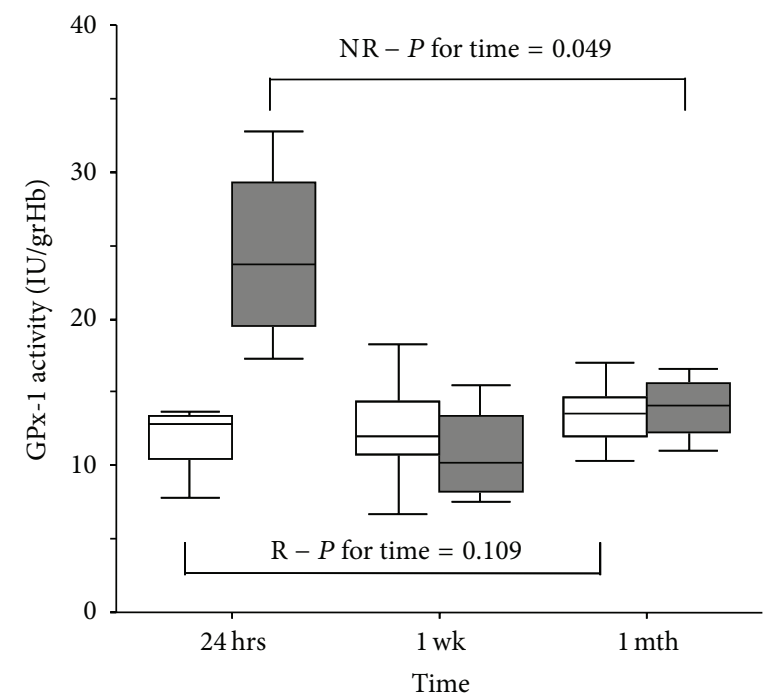

(c)

Figure 3: Profile of levels of blood reduced GSH (a), blood total GSH (b), and GPx-1 activities (c) in NR and R patients (R: empty box-plots; NR: dark box-plots). $P$ for time refers to time-dependent changes ( 24 hours, 1 week, and 1 month) in groups assessed by nonparametric Friedman test.

in response to antiplatelet therapy in ACS patients is poorly understood. In our study, the circulating levels of MIP-1 $\beta$ were found higher in NR than in $\mathrm{R}$ patients suggesting a greater tendency for the recruitment of monocytes. Likewise, few data are available regarding chemokine (C-X-C motif) receptor 3 (CXCR3) in response to antiplatelet therapy in ACS patients. CXCR3 receptor, preferentially expressed on activated Thl-cell population, is known to be involved in the recruitment of circulating activated immune cells [24]. CXCR3 receptor is activated by IFN- $\gamma$-inducible chemokines such as CXCL9, CXCL10 (IP-10), and CXCL11 (I-TAC), which are highly expressed in atherosclerotic lesions and play an important role in Thl-cell homing. Gori et al. reported higher levels of IP-10 in ACS patients on dual antiplatelet therapy with residual platelet reactivity, characterized also by elevated levels of IFN- $\gamma$ with respect to R patients [11]. In our NR patients, despite confirmed higher levels of IFN- $\gamma$, circulating levels of I-TAC were lower. Altogether, these data support an involvement of CXCR3-binding chemokines in response to clopidogrel-based therapy in ACS patients, even if these data are not conclusive.

Of note, the levels of proinflammatory cytokine IL-6 decreased significantly only in $\mathrm{R}$ patients over time while the levels of anti-inflammatory cytokine IL-1ra are maintained elevated. These results suggest the presence of a more balanced inflammatory milieu in $\mathrm{R}$ with respect to NR patients; 


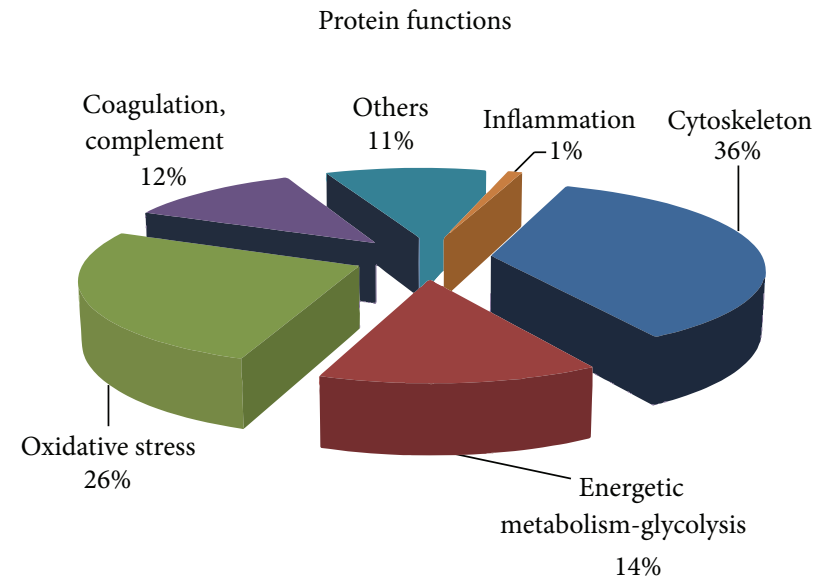

Figure 4: Pie charts of the 74 identified proteins. Proteins are divided on the basis of their functions based on Gene Ontology database (http://www.geneontology.org/).

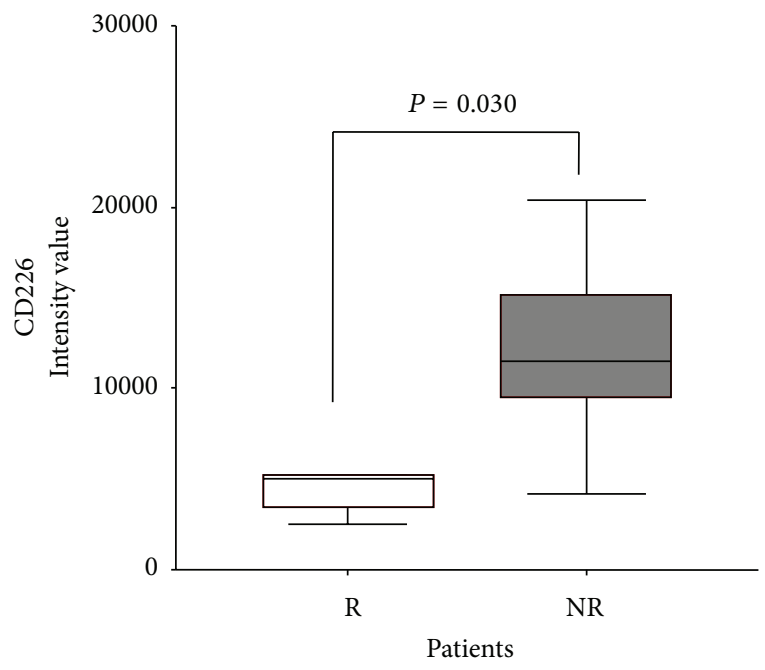

(a)

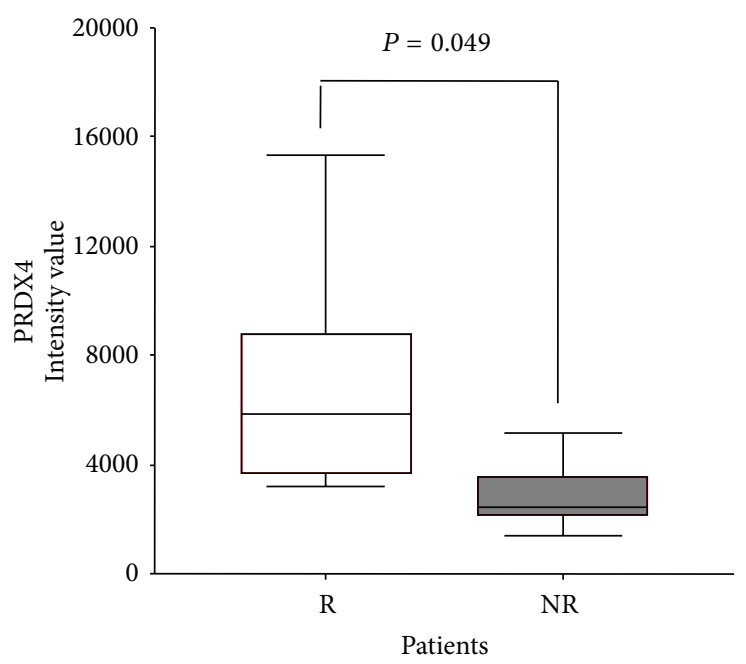

(b)

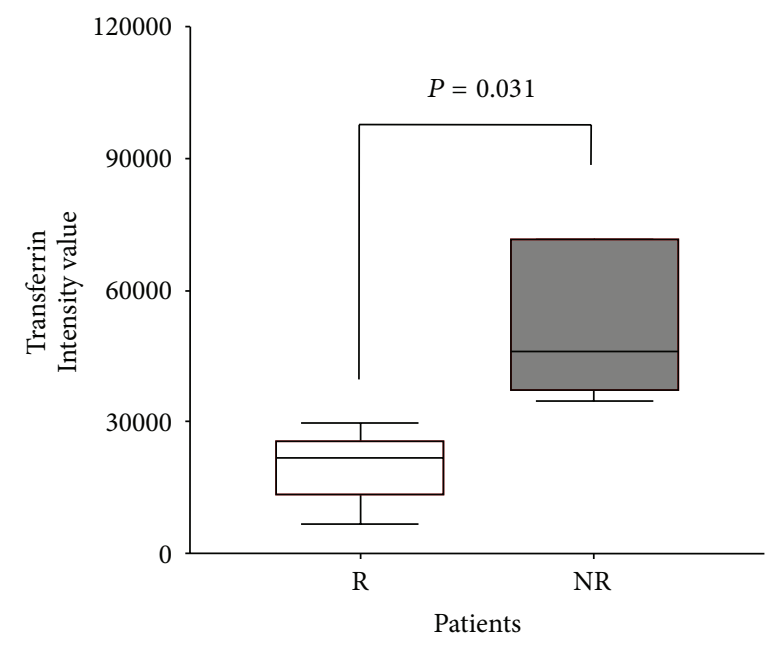

(c)

FIGURE 5: Platelet protein expression of CD226 (a), PRDX4 (b), and transferrin (c) in NR and R patients (R: empty box-plots; NR: dark box-plots). 
this impression is furthermore reinforced by elevated levels of IL- 6 and MIP- $1 \beta$, also persisting after one month from acute event.

In our study, the analysis of redox pattern has evidenced significantly lower levels of $\mathrm{r}-\mathrm{GSH}_{\mathrm{bl}}$ in the acute phase of NR compared to $\mathrm{R}$ patients. These data support the hypothesis that NR patients, during the acute phase, also present GSH depletion in addition to altered IL- 4 and MIP- $1 \beta$ levels. Several studies suggest a critical role of ROS and of low molecular weight thiols, such as GSH, in modulation of platelet activation [25, 26]. In particular, in type-2 diabetes, the platelet hyperreactivity appears to be due to both deficiency of intraplatelet antioxidant status and reduced bioavailability of antithrombotic NO [27]. In ACS patients, the GSH-defective redox milieu might reflect a condition of oxidative stress or an increased production of ROS contributing to residual platelet reactivity. These findings are consistent with recent data by Becatti et al. [28] showing that ROS production is strictly correlated to the platelet aggregation and can be predictor of poor responsiveness to dual antiplatelet treatment. Moreover, the inverse correlations between the levels of $\mathrm{GSH}_{\mathrm{bl}}$ and inflammatory parameters, such as IL-4 and I-TAC levels, suggest that the redox pattern, GSH-defective, might also affect the inflammatory pathway in ACS patients. Unlike the inflammatory state, the redox status in NR varies over time during therapy reaching the levels of the $\mathrm{R}$ patients (in particular the blood reduced GSH level and GPx-1 activity). This phenomenon might reflect a persistent action of the antioxidant system against oxidative stress. Nevertheless, the persistence of a greater inflammation in NR patients over time during antiplatelet therapy supports a more crucial role of the inflammation than redox state in response to clopidogrel.

Even analyzing the protein profile of platelets in a limited cohort of patients, the differential modulation of specific inflammatory and redox signals, in platelets of patients presenting different response to antiplatelet therapy, is confirmed and other involved markers are evidenced. CD226, a platelet adhesion molecule, is found overexpressed in platelet proteome of $\mathrm{R}$ patients [29]. In NR patients, the upregulation of platelet CD226 and the elevated levels of plasma MIP-1 $\beta$ highlight the presence of inflammatory mechanisms that promote adhesion of platelets and monocytes to vascular endothelial cells. Otherwise, the levels of PRDX4, an antioxidant enzyme crucial for the detoxification of hydrogen peroxide and superoxide, are reduced in NR patients. Accordingly, decreased platelet antioxidant content is known to be related to increased platelet aggregation [30]. TRFE minimizes the ability of circulating free iron to catalyze formation of free radicals. Indeed, TRFE levels are found reduced in patients with acute ischemic stroke, in conjunction with reduced values of the antioxidants GSH and GPx [31, 32]; furthermore, also thiols can reduce TRFE generating an increase of oxygen-derived free radicals [33]. Additionally, in presence of TRFE, a significant increase in lipid and protein oxidation and a decrease in GSH levels were observed in platelets [34]. Therefore, the different expression of PRDX 4 and TRFE between R and NR and the low levels of blood GSH in NR highlight the role of redox-sensitive signals on platelet and the importance that these molecules could have in the effectiveness of clopidogrel-based therapy.

4.1. Study Limitations. A major limitation of this study is the restricted number of investigated patients. However, the simultaneous evaluation of inflammatory mediators and oxidative stress molecules in the bloodstream, over time during therapy, associated with the analysis of the platelet protein profile of ACS patients who differently respond to clopidogrel, makes it possible to provide an overview of the main modulated players in high RPR on clopidogrel therapy. Moreover, aspirin resistance and the relationship with high RPR on clopidogrel were not assessed and need further investigation.

\section{Conclusions}

The upregulation of circulating and platelet adhesion molecules and the presence of a defective platelet antioxidant system suggest that oxidative stress and inflammatory signals might favor platelet hyperactivity, which may be associated with clopidogrel response variability. Proinflammatory milieu persists in NR patients even at a late stage after the acute event, while the antioxidant molecules tend to conform to that of patients with normal responsiveness. An unbalance of inflammation and oxidation markers is not unexpected in the acute phase but follow-up evaluation evidences differential time-course between responders and nonresponders. A phenotypic fingerprint associated with high RPR in clopidogrel treatment is evidenced suggesting additional factors that might be potentially exploited as clinically useful predictors of resistance-related poststent complications.

\section{Abbreviations}

$\begin{array}{ll}\text { ACS: } & \text { Acute coronary syndrome } \\ \text { ADP: } & \text { Adenosine } 5^{\prime} \text {-diphosphate } \\ \text { ASA: } & \text { Aspirin } \\ \text { CD: } & \text { Cluster of differentiation } \\ \text { CH}_{3} \text { CN: } & \text { Acetonitrile } \\ \text { CXCL: } & \text { Chemokine (C-X-C motif) ligand } \\ \text { CXCR: } & \text { Chemokine (C-X-C motif) receptor } \\ \text { GPX-1: } & \text { GSH peroxidase type-1 } \\ \text { Hcy: } & \text { Homocysteine } \\ \text { HPLC: } & \text { High-performance liquid chromatography } \\ \text { IFN- } \gamma: & \text { Interferon-gamma } \\ \text { IL: } & \text { Interleukin } \\ \text { IL-1ra: } & \text { Receptor antagonist of IL-1 } \\ \text { IP-10, I-TAC: } & \text { Interferon-inducible T cell alpha } \\ & \text { chemoattractant } \\ \text { I-TAC: } & \text { Interferon-gamma-induced protein } 10 \\ \text { LC-MSMS: } & \text { Liquid chromatography-tandem mass } \\ & \text { spectrometry } \\ \text { MCP-1: } & \text { Monocyte chemotactic protein-1 } \\ \text { MIP-1 } \beta: & \text { Macrophage inflammatory protein-1 } \beta \\ \text { NO: } & \text { Nitric oxide } \\ \text { NR: } & \text { Nonresponders } \\ \text { PCA: } & \text { Principal component analysis } \\ \text { PCI: } & \text { Percutaneous coronary intervention } \\ & \end{array}$


PRDX4: Peroxiredoxin-4

PRP: Platelet-rich plasma

R: $\quad$ Responders

$\mathrm{r}-\mathrm{GSH}_{\mathrm{bl}}$ : Reduced form of blood GSH

ROS: Reactive oxidant species

$\mathrm{t}-\mathrm{GSH}_{\mathrm{bl}}$ : Total forms of blood GSH

TNF- $\alpha$ : Tumor necrosis factor alpha

TRFE: Transferrin.

\section{Conflict of Interests}

There is no conflict of interests to disclose.

\section{Acknowledgment}

This study was partially supported by an unrestricted grant from the Italian Health Ministry to the Tuscany Region for the Finalized Medical Research Program 2007 (Grant agreement 2007-2-634165, APICE: Genomics and Proteomics of Antiplatelet Therapy Resistance).

\section{References}

[1] R. Abbate, G. Cioni, I. Ricci, M. Miranda, and A. M. Gori, "Thrombosis and acute coronary syndrome," Thrombosis Research, vol. 129, no. 3, pp. 235-240, 2012.

[2] E. Braunwald, D. Angiolillo, E. Bates et al., "Antiplatelet strategies: evaluating their current role in the setting of acute coronary syndromes," Clinical Cardiology, vol. 31, no. 3, pp. I2I9, 2008.

[3] E. Braunwald, D. Angiolillo, E. Bates et al., "Clinical considerations with the use of antiplatelet therapy in patients undergoing percutaneous coronary intervention," Clinical Cardiology, vol. 31, no. 3, pp. I28-I35, 2008.

[4] F. Sofi, R. Marcucci, A. M. Gori, B. Giusti, R. Abbate, and G. F. Gensini, "Clopidogrel non-responsiveness and risk of cardiovascular morbidity: an updated meta-analysis," Thrombosis and Haemostasis, vol. 103, no. 4, pp. 841-848, 2010.

[5] L. Bonello, U. S. Tantry, R. Marcucci et al., "Consensus and future directions on the definition of high on-treatment platelet reactivity to adenosine diphosphate," Journal of the American College of Cardiology, vol. 56, no. 12, pp. 919-933, 2010.

[6] G. Parodi, R. Marcucci, R. Valenti et al., "High residual platelet reactivity after clopidogrel loading and long-term cardiovascular events among patients with acute coronary syndromes undergoing PCI," Journal of the American Medical Association, vol. 306, no. 11, pp. 1215-1223, 2011.

[7] P. A. Gurbel and U. S. Tantry, "Clopidogrel resistance?” Thrombosis Research, vol. 120, no. 3, pp. 311-321, 2007.

[8] M. Śpiewak, Ł. A. Małek, G. Kostrzewa et al., "Influence of C3435T multidrug resistance gene-1 (MDR-1) polymorphism on platelet reactivity and prognosis in patients with acute coronary syndromes," Kardiologia Polska, vol. 67, no. 8, pp. 827834, 2009.

[9] S. Margetic, "Inflammation and haemostasis," Biochemia Medica, vol. 22, no. 1, pp. 49-62, 2012.

[10] P. Osmancik, P. Paulu, P. Tousek, V. Kocka, and P. Widimsky, "High leukocyte count and interleukin-10 predict high on-treatment-platelet- reactivity in patients treated with clopidogrel," Journal of Thrombosis and Thrombolysis, vol. 33, no. 4, pp. 349-354, 2012.

[11] A. M. Gori, F. Cesari, R. Marcucci et al., "The balance between pro- and anti-inflammatory cytokines is associated with platelet aggregability in acute coronary syndrome patients," Atherosclerosis, vol. 202, no. 1, pp. 255-262, 2009.

[12] F. Violi and P. Pignatelli, "Platelet oxidative stress and thrombosis," Thrombosis Research, vol. 129, no. 3, pp. 378-381, 2012.

[13] D. W. Essex, "Redox control of platelet function," Antioxidants and Redox Signaling, vol. 11, no. 5, pp. 1191-1225, 2009.

[14] J. Campolo, S. Penco, E. Bianchi et al., "Glutamate-cysteine ligase polymorphism, hypertension, and male sex are associated with cardiovascular events. Biochemical and genetic characterization of Italian subpopulation," The American Heart Journal, vol. 154, no. 6, pp. 1123-1129, 2007.

[15] J. Malinowska and B. Olas, "Analysis of biological properties of selected elements of haemostasis after treatment with the oxidized form of homocysteine in vitro," Platelets, vol. 22, no. 8, pp. 629-632, 2011.

[16] M. G. Signorello, A. Segantin, M. Passalacqua, and G. Leoncini, "Homocysteine decreases platelet NO level via protein kinase C activation," Nitric Oxide: Biology and Chemistry, vol. 20, no. 2, pp. 104-113, 2009.

[17] A. J. López-Farré, P. J. Mateos-Cáceres, D. Sacristán et al., "Relationship between vitamin D binding protein and aspirin resistance in coronary ischemic patients: a proteomic study," Journal of Proteome Research, vol. 6, no. 7, pp. 2481-2487, 2007.

[18] E. Volpi, L. Giusti, F. Ciregia et al., "Platelet proteome and clopidogrel response in patients with stable angina undergoing percutaneous coronary intervention," Clinical Biochemistry, vol. 45, no. 10-11, pp. 758-765, 2012.

[19] R. Paniccia, E. Antonucci, N. Maggini et al., "Comparison of methods for monitoring residual platelet reactivity after clopidogrel by point-of-care tests on whole blood in high-risk patients," Thrombosis and Haemostasis, vol. 104, no. 2, pp. 287292, 2010.

[20] P. Buonamici, R. Marcucci, A. Migliorini et al., "Impact of platelet reactivity after clopidogrel administration on drugeluting stent thrombosis," Journal of the American College of Cardiology, vol. 49, no. 24, pp. 2312-2317, 2007.

[21] I. Fricke, D. Mitchell, F. Petersen, A. Böhle, S. Bulfone-Paus, and S. Brandau, "Platelet factor 4 in conjunction with IL-4 directs differentiation of human monocytes into specialized antigenpresenting cells," The FASEB Journal, vol. 18, no. 13, pp. 15881590, 2004.

[22] C. M. Weyand, J. J. Goronzy, G. Liuzzo, S. L. Kopecky, D. R. Holmes Jr., and R. L. Frye, "T-cell immunity in acute coronary syndromes," Mayo Clinic Proceedings, vol. 76, no. 10, pp. 10111020, 2001.

[23] K. L. Jones, J. J. Maguire, and A. P. Davenport, "Chemokine receptor CCR5: from AIDS to atherosclerosis," British Journal of Pharmacology, vol. 162, no. 7, pp. 1453-1469, 2011.

[24] S. Lacotte, S. Brun, S. Muller, and H. Dumortier, "CXCR3, inflammation, and autoimmune diseases," Annals of the New York Academy of Sciences, vol. 1173, pp. 310-317, 2009.

[25] B. Olas and B. Wachowicz, "Role of reactive nitrogen species in blood platelet functions," Platelets, vol. 18, no. 8, pp. 555-565, 2007.

[26] F. Krötz, H.-Y. Sohn, and U. Pohl, "Reactive oxygen species: players in the platelet game," Arteriosclerosis, Thrombosis, and Vascular Biology, vol. 24, no. 11, pp. 1988-1996, 2004. 
[27] K. R. Gibson, T. J. Winterburn, F. Barrett, S. Sharma, S. M. MacRury, and I. L. Megson, "Therapeutic potential of Nacetylcysteine as an antiplatelet agent in patients with type-2 diabetes," Cardiovascular Diabetology, vol. 10, article 43, 2011.

[28] M. Becatti, C. Fiorillo, A. M. Gori et al., "Platelet and leukocyte ROS production and lipoperoxidation are associated with high platelet reactivity in Non-ST elevation myocardial infarction (NSTEMI) patients on dual antiplatelet treatment," Atherosclerosis, vol. 231, no. 2, pp. 392-400, 2013.

[29] H. Kojima, H. Kanada, S. Shimizu et al., "CD226 mediates platelet and megakaryocytic cell adhesion to vascular endothelial cells," Journal of Biological Chemistry, vol. 278, no. 38, pp. 36748-36753, 2003.

[30] D. del Principe, G. Frega, I. Savini, M. V. Catani, A. Rossi, and L. Avigliano, "The plasma membrane redox system in human platelet functions and platelet-leukocyte interactions," Thrombosis and Haemostasis, vol. 101, no. 2, pp. 284-289, 2009.

[31] I. M. Cojocaru, M. Cojocaru, V. Sapira, and A. Ionescu, "Evaluation of oxidative stress in patients with acute ischemic stroke," Romanian Journal of Internal Medicine, vol. 51, no. 2, pp. 97-106, 2013.

[32] D. L. Steen, C. P. Cannon, S. S. Lele et al., "Prognostic evaluation of catalytic iron in patients with acute coronary syndromes," Clinical Cardiology, vol. 36, no. 3, pp. 139-145, 2013.

[33] M. Prakash, "Role of non-transferrin-bound iron in chronic renal failure and other disease conditions," Indian Journal of Nephrology, vol. 17, no. 4, pp. 188-193, 2007.

[34] A. Sener, O. Cevik, G. Yanikkaya-Demirel, S. Apikoglu-Rabus, and D. Ozsavci, "Influence of platelet $\gamma$-glutamyltransferase on oxidative stress and apoptosis in the presence of holotransferrin," Folia Biologica, vol. 58, no. 5, pp. 193-202, 2012. 


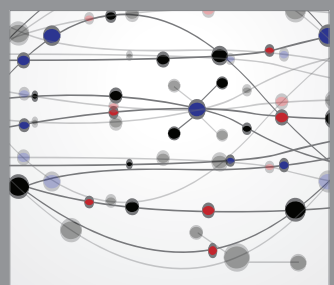

The Scientific World Journal
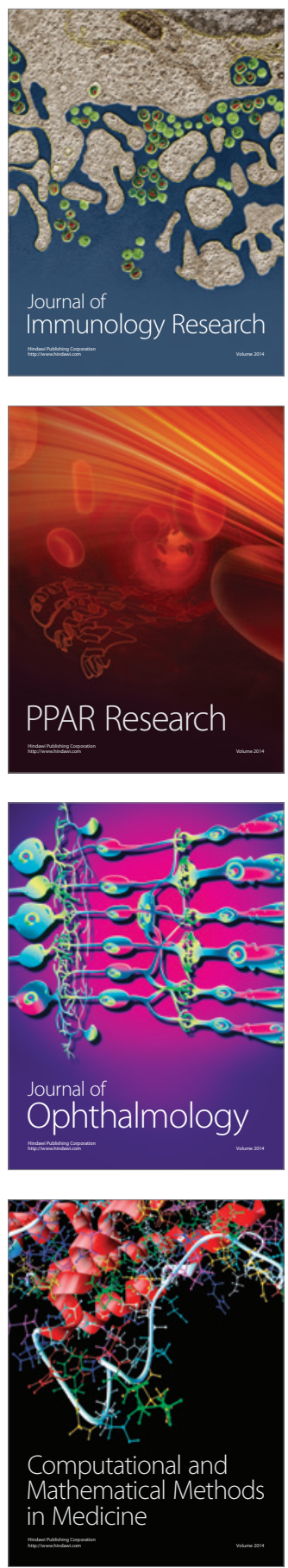

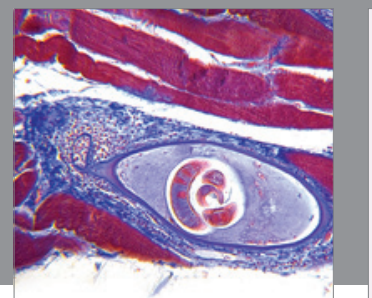

Gastroenterology

Research and Practice
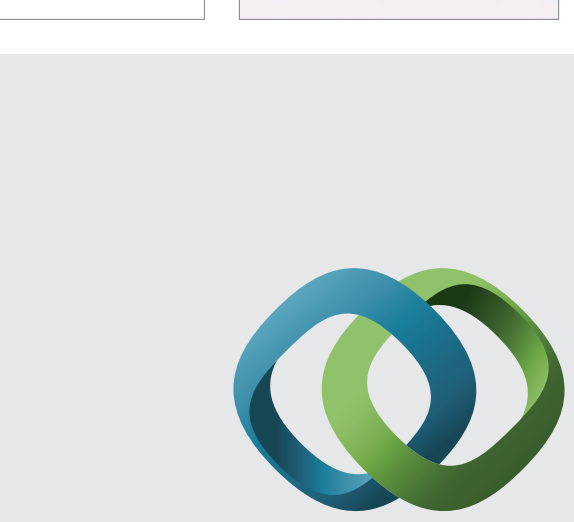

\section{Hindawi}

Submit your manuscripts at

http://www.hindawi.com
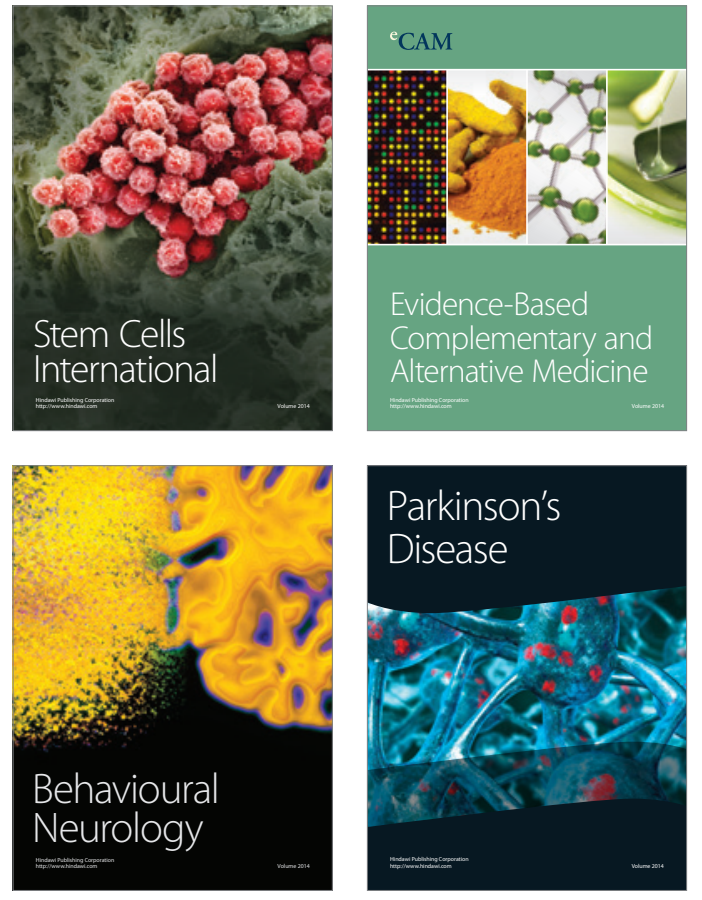
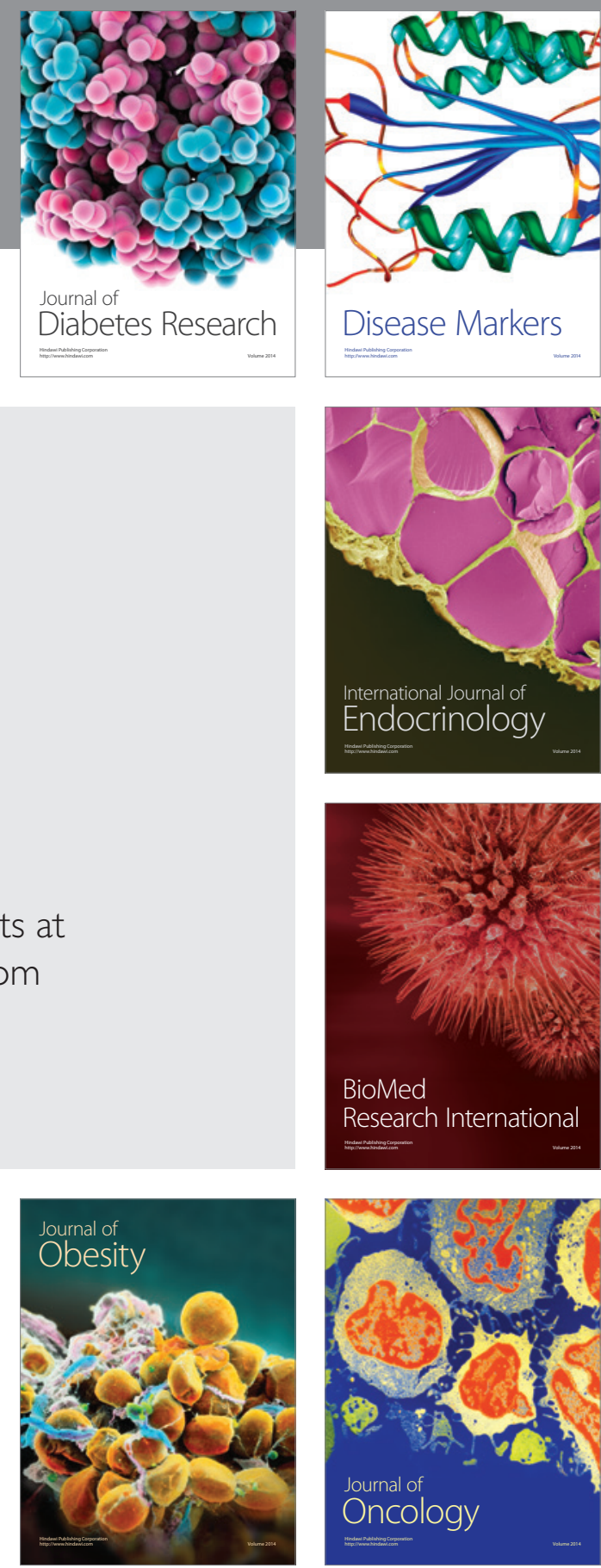

Disease Markers
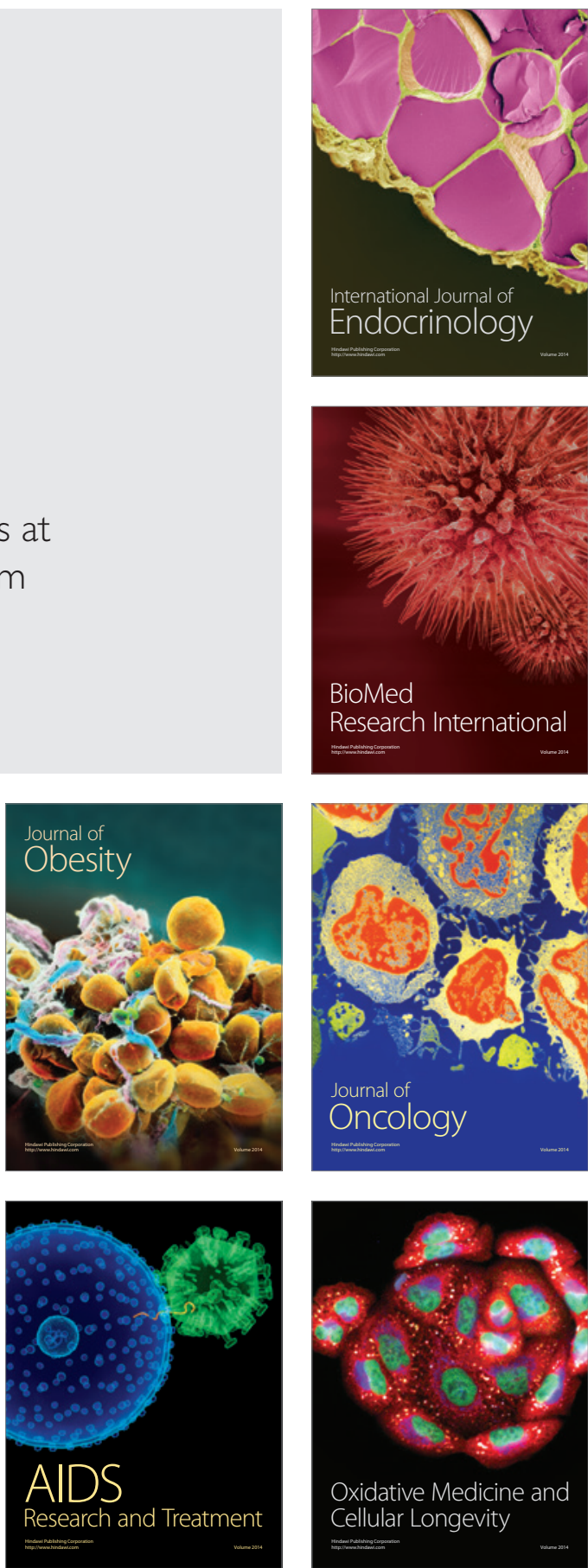